\title{
A meta-analysis and critical evaluation of influencing factors on soil carbon priming following biochar amendment
}

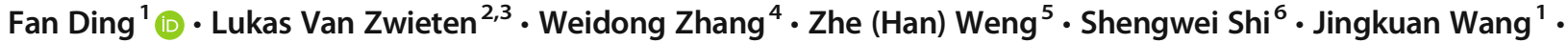 \\ Jun Meng ${ }^{7}$
}

Received: 2 June 2017 / Accepted: 12 December 2017

(C) Springer-Verlag GmbH Germany, part of Springer Nature 2017

\begin{abstract}
Purpose Previous studies have found biochar-induced effects on native soil organic carbon (NSOC) decomposition, with a range of positive, negative and no priming reported. However, many uncertainties still exist regarding which parameters drive the amplitude and the direction of the biochar priming.

Materials and methods We conducted a quantitative analysis of 1170 groups of data from 27 incubation studies using boosted regression trees (BRTs). BRT is a machine learning method combining regression trees and a boosting algorithm, which can effectively partition independent influences of various factors on the target variable in the complex ecological processes.

Results and discussion The BRT model explained a total of $72.4 \%$ of the variation in soil carbon (C) priming following biochar amendment, in which incubation conditions (36.5\%) and biochar properties (33.7\%) explained a larger proportion than soil properties $(29.8 \%)$. The predictors that substantially accounted for the explained variation included incubation time $(27.1 \%)$ and soil moisture (5.0\%), biochar $\mathrm{C} / \mathrm{N}$ ratio (6.2\%), nitrogen content (5.5\%), pyrolysis time during biochar production (5.1\%), biochar $\mathrm{pH}(4.5 \%)$, soil $\mathrm{C}$ content $(5.2 \%)$, sand $(4.7 \%)$ and clay content (4.1\%). In contrast, other incubation conditions (temperature, biochar dose, whether nutrient was added), biochar properties (biochar $\mathrm{C}$, feedstock type, ash content, pyrolysis temperature, whether biochar was activated) and soil properties (nitrogen content, silt content, $\mathrm{C} / \mathrm{N}$ ratio, $\mathrm{pH}$, land use type) had small contribution (each $<4 \%$ ). Positive priming occurred within the first 2 years of incubations, with a change to negative priming afterwards. The priming was negative for low $\mathrm{N}$ biochar or in high-moisture soils but positive on their reverse sides. The size of negative priming increased with rising biochar $\mathrm{C} / \mathrm{N}$ ratio, pyrolysis time and soil clay content, but deceased with soil $\mathrm{C} / \mathrm{N}$ ratio.

Conclusions We determine the critical drivers for biochar effect on native soil organic $\mathrm{C}$ cycling, which can help us to better predict soil $\mathrm{C}$ sequestration following biochar amendment.
\end{abstract}

Responsible editor: Hailong Wang

Electronic supplementary material The online version of this article (https://doi.org/10.1007/s11368-017-1899-6) contains supplementary material, which is available to authorized users.

Fan Ding

dingfan1985@syau.edu.cn

Weidong Zhang

wdzhang@iae.ac.cn

1 College of Land and Environment, Shenyang Agricultural University, Dongling Rd, Shenyang 110866, People's Republic of China

2 New South Wales Department of Primary Industries, Wollongbar, NSW 2477, Australia

3 Southern Cross Plant Science, Southern Cross University, East Lismore, NSW 2480, Australia
4 Key Laboratory of Forest Ecology and Management, Institute of Applied Ecology, Chinese Academy of Sciences, Shenyang 110164, People's Republic of China

5 New South Wales Department of Primary Industries, Wagga Wagga, NSW 2650, Australia

$6 \quad$ Plant Science and Technology College, Beijing University of Agriculture, Beijing 102206, People's Republic of China

7 Liaoning Biochar Engineering \& Technology Research Center, Shenyang Agricultural University, Dongling Rd, Shenyang 110866, People's Republic of China 
Keywords Boosted regression tree $\cdot$ Incubation time $\cdot$ Native soil organic matter $\cdot$ Priming effect $\cdot$ Pyrogenic organic matter $\cdot$ Soil respiration

\section{Introduction}

During the last decade, biochar has rapidly gained attention not only from the scientific community but also from policymakers and farmers, due to its multifaceted benefits to agriculture and the environment (Lehmann 2007). Biochar is a carbon (C)-rich product obtained when biomass, such as wood, manure or crop residue, is pyrolysed with little or no available oxygen (Lehmann and Joseph 2009). It has also been referred to as pyrogenic organic matter (Maestrini et al. 2014a) or charcoal (Wardle et al. 2008). Here, we define biochar as a collective group of pyrogenic organic matter applied as a soil amendment. Due to the aromatic nature of $\mathrm{C}$ in biochar, it possesses a degree of recalcitrance in soil with mean residence times reported between hundreds to thousands of years (Schmidt et al. 2002; Kuzyakov et al. 2009). This property makes it a valuable tool for soil C sequestration (Lehmann et al. 2006; Woolf et al. 2010; Ciais et al. 2013).

However, the amendment of soil with biochar may also affect the decomposition of native soil organic carbon (NSOC). When biochar addition stimulates NSOC decomposition (i.e. positive priming), its benefit to $\mathrm{C}$ sequestration will be partially compromised (Wardle et al. 2008). When biochar reduces NSOC decomposition (i.e. negative priming), its $\mathrm{C}$ sequestration potential will be greater than expected (Woolf and Lehmann 2012). Many incubation studies have tested the impacts of biochar on NSOC decomposition, but results have been inconsistent. Positive priming of NSOC (Wardle et al. 2008; Luo et al. 2011), negative priming (Jones et al. 2011; Lu et al. 2014b), and no effect (Santos et al. 2012; Nguyen et al. 2014) have been reported. Previous incubation studies reported that biochar priming was affected by factors including biochar properties such as pyrolysis temperature and feedstock type (Zimmerman et al. 2011; Singh and Cowie 2014), soil properties such as $\mathrm{pH}$ (Luo et al. 2011) and C content (Stewart et al. 2013) and incubation conditions including soil moisture (Yu et al. 2013) and soil temperature (Fang et al. 2015). However, many uncertainties still exist on the parameters driving the amplitude and the direction of the biochar priming (Maestrini et al. 2014a). Apparently, a synthesis of the data from published papers and a comprehensive understanding of the relation between biochar-induced soil $\mathrm{C}$ priming and its determining factors are needed. Although two recent metaanalyses have summarized the influencing factors for biochar effect on NSOC decomposition (Maestrini et al. 2014a; Wang et al. 2015), they neither included incubation conditions (e.g. incubation temperature and moisture) nor compared the importance of the factors for driving the biochar-induced $\mathrm{C}$ priming. Moreover, there are many new empirical papers published in recent years that need to be incorporated to the database to give an updated result.

In this study, we conducted a synthesis to analyse 1170 groups of data from 27 controlled incubation studies. The data included NSOC decomposition rates, under the treatments of biochar amendment and without biochar amendment, and corresponding soil properties (land use, clay, silt and sand content, $\mathrm{pH}$, soil organic $\mathrm{C}$ (SOC) and soil total nitrogen (STN) content and $\mathrm{C} / \mathrm{N}$ (nitrogen) ratio), biochar properties (feedstock type, pyrolysis time and temperature, activation, $\mathrm{pH}, \mathrm{C}$ and $\mathrm{N}$ contents, $\mathrm{C} / \mathrm{N}$ ratio, ash content) and incubation conditions (temperature, moisture, incubation time, biochar dose and mineral nutrient addition). The aim is to determine the critical factors driving the amplitude and the direction of the biochar priming on NSOC decomposition in well-controlled incubation studies.

\section{Material and methods}

\subsection{Data collection}

We performed a systematic literature search of peer-reviewed publications on the effect of biochar addition on NSOC decomposition using the Web of Science database. The cut-off date was 15 August 2017. We collected data from studies that provide NSOC decomposition rates in soils with biochar amendment and without biochar amendment (control), according to the following criteria: (1) We only chose incubation studies rather than field studies, because in the field, it may have higher soil moisture or temperature in the biochar treatment than in the control (Lu et al. 2014a; Malghani et al. 2015; Ventura et al. 2015), impacting observed results for biocharinduced $\mathrm{C}$ priming; (2) $\mathrm{C}$ isotope $\left({ }^{13} \mathrm{C}\right.$ or $\left.{ }^{14} \mathrm{C}\right)$ of emitted $\mathrm{CO}_{2}$ must be measured, so it can differentiate the quantity of $\mathrm{CO}_{2}$ derived from biochar and from NSOC; (3) the incubated biochar-amended soil must be without growing plants and without further organic material addition; (4) when the soil was incubated with mineral nutrient addition, similar mineral treatments were required between biochar amendments and controls; (5) the soil must experience the process of pedogenesis, so the data for loess (like soil parent material) in Kuzyakov et al. (2009) was excluded; (6) biochar must be unprocessed other than by activation (partial gasification with steam) and produced under zero or limited oxygen conditions enabling better understanding and replication of the properties of the biochar that impact priming. Thus, the data for (1) 
artificially weathered biochar described in Naisse et al. (2015b), (2) biochar with DOC extracted in Whitman et al. (2014), (3) hydrothermal biochar in Naisse et al. (2015b)) and (4) char produced under full atmosphere (enough oxygen) in Zimmerman et al. (2011) were excluded.

Subsequently, in order to take into account the effect of incubation time on the biochar-induced priming, we extracted the paired data of NSOC decomposition rates of biochar treatment $\left(X_{\mathrm{e}}\right)$ and control $\left(X_{\mathrm{c}}\right)$ at different sampling dates from text, tables or figures in the collected studies. The data presented in figures were obtained using OriginPro 7.5 software (OriginLab, Northampton, MA, USA) with the 'Digitize. OPK' plug-in. The procedure may result in the collected data including more data points from some studies with multiple sampling times than other studies with a few sampling times. However, it will not bring different weights between these two types on the relation between the biochar-induced soil $\mathrm{C}$ priming and predictors, since the points for multiple sampling times in the same treatment have the same property for a given predictor (expect for incubation time). Moreover, our data collection could mean that more than one experimental treatment was compared to the same control. In these instances, it artificially increased the number of replicates and may bias the results towards overconfidence (i.e. confidence intervals may be too narrow). However, the more conservative approach of using only a single average measurement for the different measures will sacrifice too much information (Sagrilo et al. 2014).

Some studies directly provided decomposition rates of NSOC under biochar amendment and control (Jones et al. 2011; Zimmerman et al. 2011; Santos et al. 2012; Fang et al. 2014; Lu et al. 2014b). However, most of the studies did not report them directly, so we performed data transformations. Some studies showed the total $\mathrm{CO}_{2}$ emission in the biochar treatment and $\mathrm{CO}_{2}$ amount derived from biochar (Kuzyakov et al. 2009; Keith et al. 2011; Naisse et al. 2015a), and the decomposition amount of NSOC was calculated by the difference. Some studies showed the cumulative $\mathrm{CO}_{2}$ emission derived from NSOC under different incubation stages (Cross and Sohi 2011; Keith et al. 2011; Bruun and El-Zehery 2012; Singh et al. 2012; Maestrini et al. 2014b; Whitman et al. 2014; Dharmakeerthi et al. 2015; Rittl et al. 2015; Cui et al. 2017). $X_{e}$ and $X_{c}$ were calculated using the following equation:

$X_{\mathrm{e}}$ or $X_{\mathrm{c}}=\left(\mathrm{CO}_{2-} \mathrm{C}_{n+1}-\mathrm{CO}_{2} \mathrm{C}_{n}\right) / t$

where $\mathrm{CO}_{2} \mathrm{C}_{n+1}$ and $\mathrm{CO}_{2} \mathrm{C}_{n}$ are the cumulative $\mathrm{CO}_{2}$-C production derived from NSOC at the $n+1$ th and $n$th sampling campaigns, respectively, and the value of $t$ is the interval time between the two sampling campaigns.
Some studies showed the remaining NSOC at different incubation durations (Nguyen et al. 2014), and it was calculated by

$X_{\mathrm{e}}$ or $X_{\mathrm{c}}=\left(\mathrm{SOC}_{n+1}-\mathrm{SOC}_{n}\right) / t$

where $\mathrm{SOC}_{n}$ and $\mathrm{SOC}_{n+1}$ are the amount of remaining NSOC at the $n$th and $n+1$ th sampling campaigns.

Some studies showed priming as $\left(X_{\mathrm{e}}-X_{\mathrm{c}}\right) / X_{\mathrm{c}}$ (Luo et al. 2011; Farrell et al. 2013; Herath et al. 2015), and we set $X_{\mathrm{c}}$ as 1 and then calculated the value of $X_{\mathrm{e}}$. When showing priming as $X_{\mathrm{e}}-X_{\mathrm{c}}$ (Naisse et al. 2015b; Yousaf et al. 2017), $X_{\mathrm{e}}$ was calculated by the addition of $X_{\mathrm{c}}$. For other cases (Murray et al. 2015; Kerré et al. 2016; Sheng et al. 2016; Luo et al. 2017), it was calculated by the combination of the above equations. If we were unable to calculate $X_{\mathrm{e}}$ and $X_{\mathrm{c}}$, the study was excluded from data collection. In total, we collected 1196 pairs of data $\left(X_{\mathrm{e}}\right.$ and $\left.X_{\mathrm{c}}\right)$ across 27 studies.

In addition to $X_{\mathrm{e}}$ and $X_{\mathrm{c}}$, the corresponding soil properties (SOC, STN, C/N ratio, $\mathrm{pH}$, clay, silt and sand contents and land use), biochar properties (feedstock type, pyrolysis temperature, pyrolysis time, whether biochar was activated, $\mathrm{C}$ and $\mathrm{N}$ content, $\mathrm{C} / \mathrm{N}$ ratio, $\mathrm{pH}$ and ash content) and incubation conditions (incubation temperature, incubation soil moisture, incubation days, biochar dose and whether nutrient was added) were also collected. SOC and STN ranged from 2 to 114 and from 0.4 to $10 \mathrm{~g} / \mathrm{kg}$, respectively. Soil $\mathrm{C} / \mathrm{N}$ ratio ranged from 7.7 to 20.2. Soil $\mathrm{pH}$ ranged from 3.7 to 8.8. Soils were under five types of land use, including cropland, fallow, grassland, forest and wetland. Pyrolysis time and temperature of producing biochar ranged from 0.025 to $48 \mathrm{~h}$ and from 300 to $1200^{\circ} \mathrm{C}$. Biochar $\mathrm{C}$ and $\mathrm{N}$ contents ranged from 16.5 to $83.9 \%$ and from 0.09 to $6.29 \%$, respectively. Biochar $\mathrm{C} / \mathrm{N}$ ratio ranged from 8 to 344 . Biochar $\mathrm{pH}$ ranged from 3.90 to 11.21 . Biochar ash content ranged from 3.0 to $57.2 \%$. Incubation temperature ranged from 20 to $60{ }^{\circ} \mathrm{C}$, and soil moisture ranged from 40 to $80 \%$ water-holding capacity (WHC), except for some data expressed as water potential or water-filled pore space (WFPS). The incubation time, attributing to the last day of a corresponding cumulative period, ranged from 0 to 2551 days. Biochar was applied between 0.07 and $20 \%$ (as dry soil weight equivalents).

\subsection{Data analysis}

The effect size (ES) for each paired observation was calculated as the natural log of the response ratio as

$\mathrm{ES}=\operatorname{Ln}\left(X_{\mathrm{e}} / X_{\mathrm{c}}\right)$

Thus, positive ES indicates an enhancement of NSOC decomposition following biochar amendment, whereas negative ES means the decrease of NSOC decomposition. The data of ES outside of three standard deviations of its mean, 26 values 
totally, were considered outliers and discarded. There were remaining 1170 groups of data (see Online Resource 1 in the Electronic Supplementary Material).

To partition independent influences of soil properties, biochar properties and incubation conditions, we used boosted regression trees (BRTs). BRT is an advanced form of machine learning method that combines regression trees and boosting algorithm (De'Ath 2007). In BRT, multiple trees are fitted and combined in a forward stage-wise procedure to predict the response of the dependent variable to multiple predictors (De'Ath 2007). BRT can simultaneously handle explainable variables of categorical and continuous types that avoids the errors introduced by artificial categorization in the common meta-analysis and does not require the distributional characteristics of the data (Nguyen et al. 2016). Further, BRT can handle missing values in predictors on the basis of 'surrogate' splitting (Zhang et al. 2015). In addition, the independence of predictors is not required in BRT because the interactions of predictors are modelled automatically by the hierarchical structure of a tree (Zhang et al. 2015). Due to the above advantages, the BRT model has been applied effectively in many ecological or environmental studies (Zhang et al. 2012, 2015; Nguyen et al. 2016).

BRT models were operated in $\mathrm{R}$ (version 2.15.2; $\mathrm{R}$ Development Core Team 2012) by using the gbm package (Elith et al. 2008). In the current BRT analysis, the Gaussian error structure was chosen for the loss function because of the attribution of our response variable (Zhang et al. 2012). There are four input settings for BRT models: (1) the learning rate determines the contribution of each tree to the growing model; (2) the tree complexity controls the level of interactions in BRT; (3) the bagging fraction sets the proportion of observations used in selecting variables; and (4) the cross-validation specifies the number of times to randomly divide the data for model fitting and validation (De'Ath 2007). To find the optimal settings, we fitted 27 BRT models with the combinations of the following settings: learning rates of $0.01,0.005$ and 0.001; bag fractions of $0.4,0.5$ and $0.6 ; 5-, 8$ - and 10-fold cross-validations; and a tree complexity of 4 to account for potential high interactions. Among the fitted models, the best model had a cross-validation deviance of 0.081 ( \pm 1 stand error $=0.005$ ) from a learning rate of 0.05 , bag fraction of 0.6 and 10 -fold cross-validation. The subsequent models were all fitted with these optimal settings. The percentage of variation in ES explained by the BRT model was calculated as $\{1$ - [(sum of squared residuals from a BRT model)/(sum of squared residuals from an intercept-only model) $]\} \times 100 \%$, where 'residuals' refer to test sample residuals (Robinson 2008). We also examined the relative influence of predictor variables to quantify the importance of predictors on the priming effect. The influence of each predictor is based on the number of times for which a variable is selected for splitting, weighted by the squared improvement to the model as a result of each split and averaged over all trees. Then, the relative importance is scaled such that the sum is 100 , and higher numbers correspond to a stronger influence on the priming effect. The net effects of predictors on priming effect average out the effects of the other predictors included in the BRT model and are visualized in partial dependence plots. Moreover, we used a bootstrap technique to estimate the 95\% confidence intervals (CI) around each variable, as the BRT cannot directly provide them. According to Carslaw and Taylor (2009), the estimation process was conducted by taking a random sample (with replacement) of the full hourly data set to generate 500 bootstrap replicates. A BRT model was fitted to each sample and predictions made for each variable in turn as described previously. These data are sorted in descending order for each variable and approximate $100 \times(1-$ $2 \alpha) \%$ confidence limits calculated.

\section{Results}

The BRT model explained in total $72.4 \%$ of the ES variation. Incubation conditions contributed $36.5 \%$ of the explanation for the variation of ES, wherein $27.1 \%$ was derived from incubation time, $5.0 \%$ from incubation moisture and the remaining $4.4 \%$ from incubation temperature, biochar dose and nutrient addition (Fig. 1). The ES decreased across the period from 0 to 206 days, increased to a peak at 773 days, then sharply decreased until 1185 days and remained relative stable following that time (Fig. 2a). The ES value decreased with soil moisture, being positive at the range of $40-57 \%$ WHC and negative from 57 to $70 \%$ WHC (Fig. 2b). The ES value slightly decreased from an incubation temperature of 20 to $50{ }^{\circ} \mathrm{C}$ (Fig. 2c). The ES value was larger for $<7.5 \% w / w$ biochar dose than $>7.5 \% w / w$ dose (Fig. 2d). Nutrient addition did not change the ES value (Fig. 2e).

Biochar properties contributed $33.7 \%$ of the explanation, wherein $6.2 \%$ was from the biochar $\mathrm{C} / \mathrm{N}$ ratio, $5.5 \%$ from biochar $\mathrm{N}$ content, $5.1 \%$ from pyrolysis time and $4.5 \%$ from biochar $\mathrm{pH}$ (Fig. 1). In contrast, other biochar properties, i.e. feedstock type, ash content, pyrolysis temperature and whether biochar was activated, independently contributed $<4 \%$, indicating that they are not relatively important to explain the variation of biochar effect on NSOC decomposition. The ES value continually decreased with biochar $\mathrm{C} / \mathrm{N}$ ratio (Fig. 3a). Correspondingly, the ES values generally increased with biochar $\mathrm{N}$ content, being negative when biochar $N<3.8 \%$ but positive when biochar $N>3.8 \%$ (Fig. 3b). The ES value continually decreased with increasing duration of pyrolysis from 0.025 to $9 \mathrm{~h}$, being constant after $9 \mathrm{~h}$ (Fig. 3c). The ES value kept constant during the range of biochar $\mathrm{pH}$ from 3.9 to 8.0, then slightly decreased from 8.0 to 10.6 , but increased when biochar $\mathrm{pH}>10.6$ (Fig. 3d). In contrast to the relationship between $\mathrm{ES}$ and biochar $\mathrm{N}$ content, the ES value decreased 


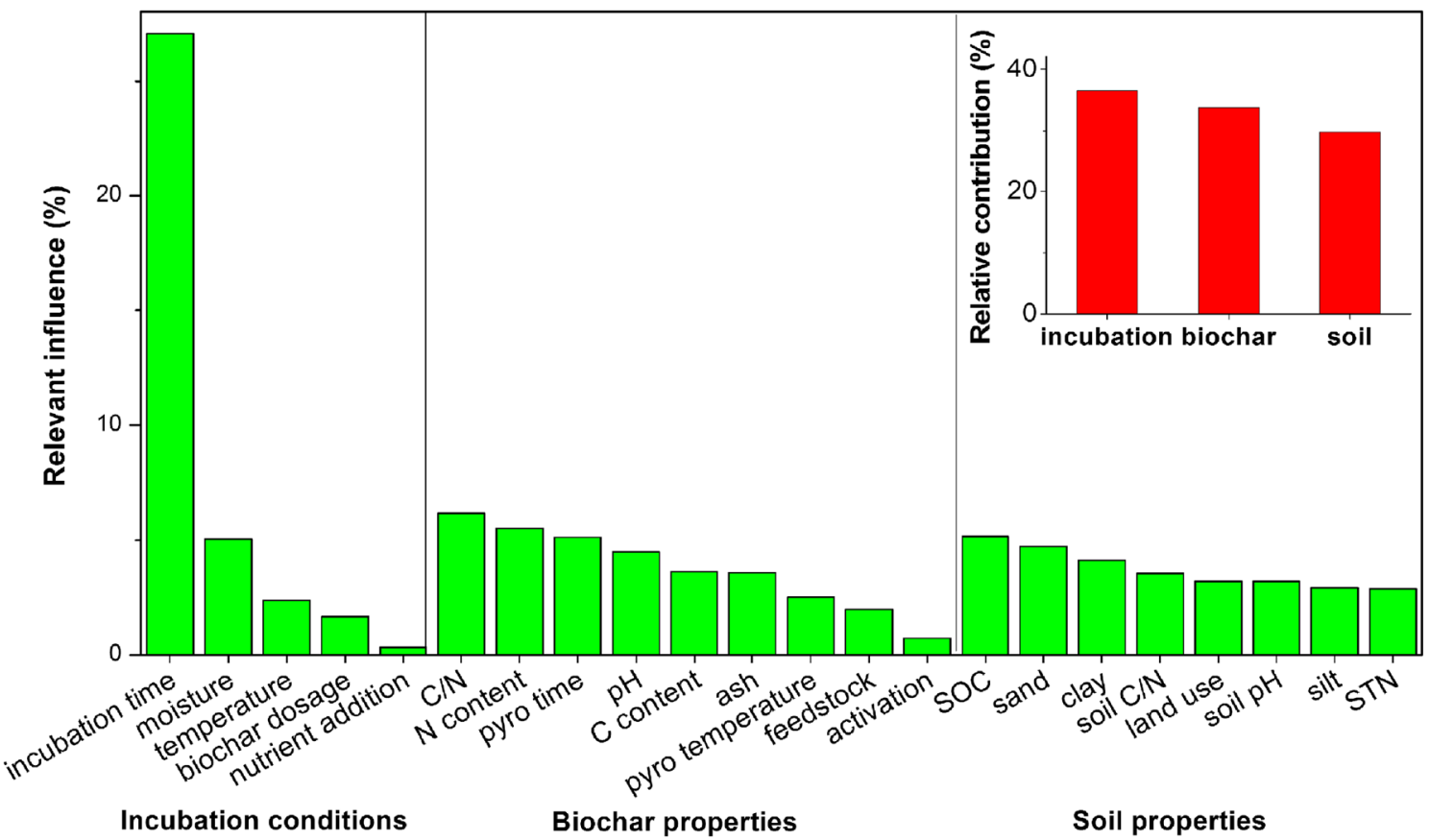

Fig. 1 Percentage relative influence of factors on the priming effect following biochar amendment. The inner figure showed the comprehensive influence of incubation conditions, biochar properties and soil properties

with increasing biochar $\mathrm{C}$, being positive at low biochar $\mathrm{C}$ content $(<37.6 \%)$ but negative at high biochar $\mathrm{C}$ content $(>37.6 \%$, Fig. 3e). The ES value did not change with increasing biochar ash content (Fig. 3f). The ES value decreased when biochar-derived pyrolysis temperature rose from 325 to $600{ }^{\circ} \mathrm{C}$ and kept almost constant after that (Fig. $3 \mathrm{~g}$ ). Among the five feedstocks, only sludge-derived biochar resulted in a significant positive priming and tree- and crop residue-derived biochar showed the lowest ES value, i.e. the largest negative priming (Fig. 3h). Biochar with activation had similar ES with biochar without activation (Fig. 3i).

Compared with incubation conditions and biochar properties, soil properties had a smaller contribution $(29.8 \%)$ to the explained variation (Fig. 1). Among the soil properties, SOC was the largest contributor
Fig. 2 Partial dependence plots showing the variation in biochar priming effect by incubation condition variables used in the BRT model. a Incubation time. b Incubation soil moisture. c Incubation temperature. d Biochar dose (\% dried soil weight). e Nutrient addition or not. The fitted function shows the relationship between ES and an explanatory variable while all other explanatory variables are kept constant at their mean level. The shading shows the $95 \%$ confidence intervals estimated, and the vertical bars show the standard deviations, from 500 bootstrap samples of the data set. The horizontal dashed line represented a predicted ES value equal to 0
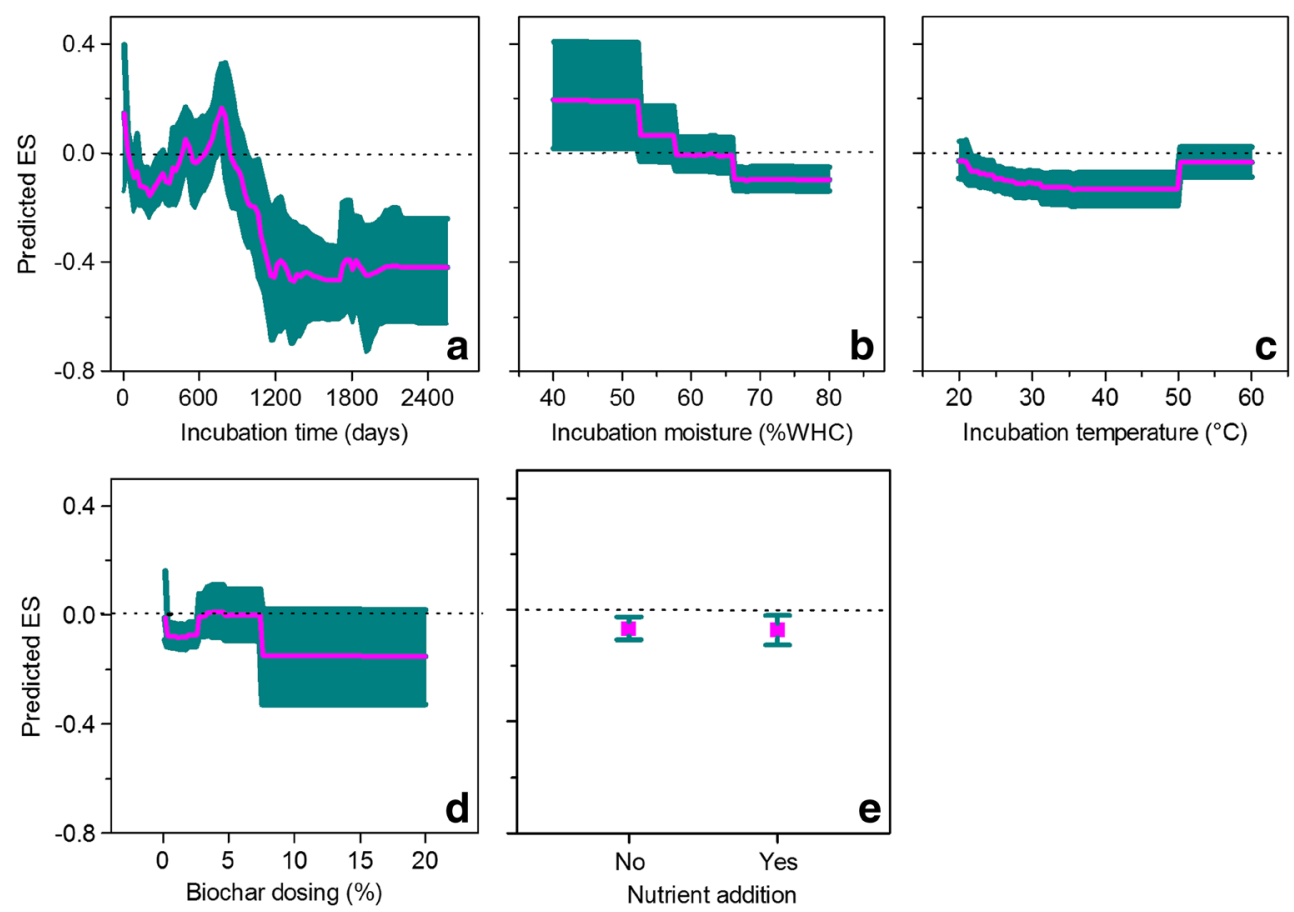
Fig. 3 Partial dependence plots showing the variation in biochar priming effect by biochar properties used in the BRT model. a $\mathrm{C} / \mathrm{N}$ ratio. b Biochar nitrogen content. c Pyrolysis time during biochar production. d Biochar $\mathrm{pH}$. e Biochar carbon content. f Ash content. g Pyrolysis temperature during biochar production. h Feedstock types. i Whether biochar was activated. The fitted function shows the relationship between ES and an explanatory variable while all other explanatory variables are kept constant at their mean level. The shading shows the $95 \%$ confidence intervals estimated, and the vertical bars show the standard deviations, from 500 bootstrap samples of the data set. The horizontal dashed line represented a predicted ES value equal to 0
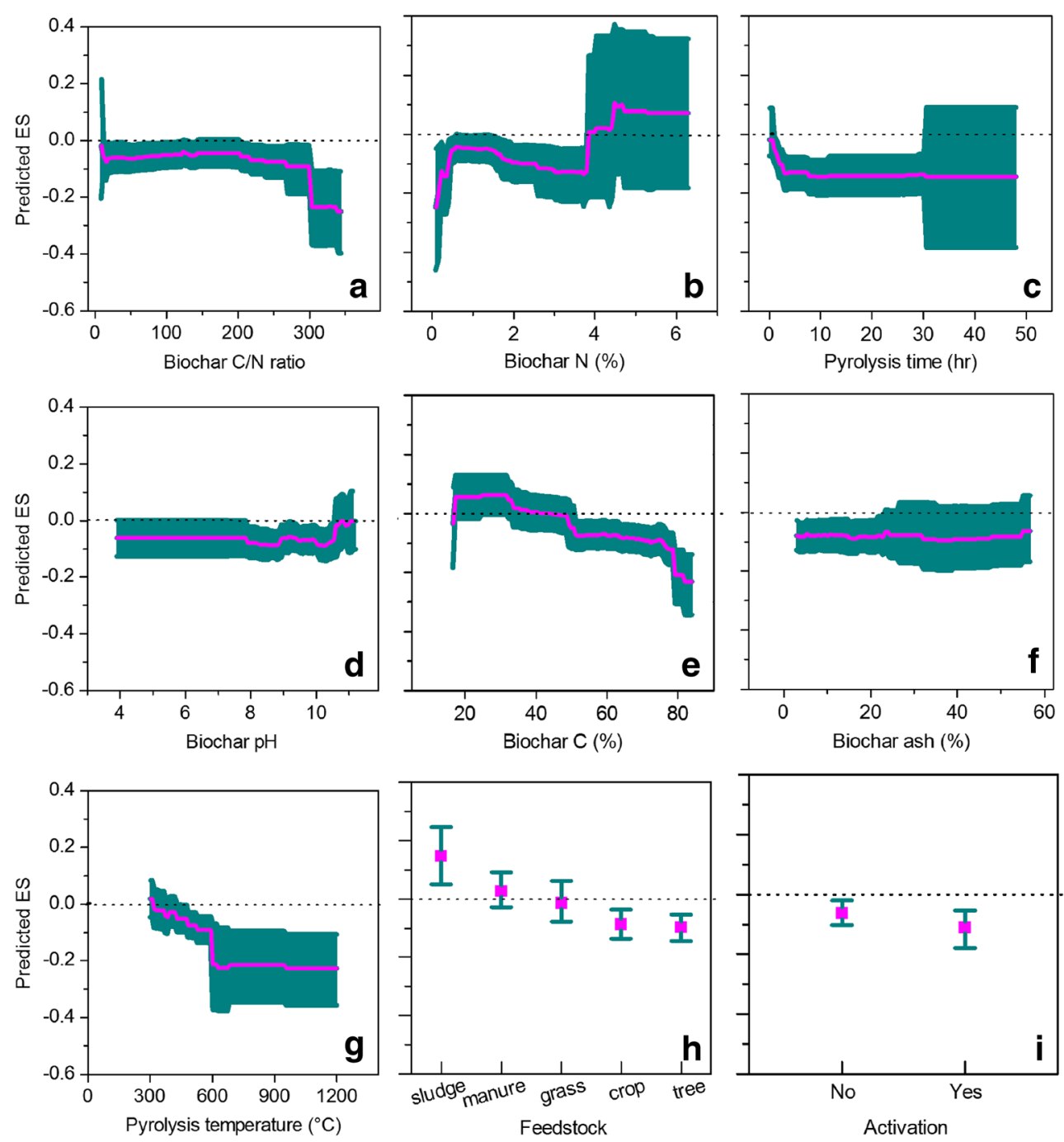

(5.2\%), and then it was sand content (4.7\%) and clay content $(4.1 \%)$. The other soil properties had minor contributions, with soil $\mathrm{C} / \mathrm{N}$ ratio $(3.6 \%)$, land use (3.2\%), soil pH (3.2\%), silt content (2.9\%) and STN $(2.9 \%)$. The ES value was positive when $\mathrm{SOC}<4 \mathrm{~g} / \mathrm{kg}$, but sharply decreased to -1 when $\mathrm{SOC}=4 \mathrm{~g} / \mathrm{kg}$ and then kept generally constant after that (Fig. 4a). The ES value increased with sand content from 4 to $35 \%$, then kept constant from 35 to $60 \%$, but decreased when sand content was larger than $60 \%$ (Fig. 4b). In contrast, the ES value changed slightly with clay content from 1 to $54 \%$ but continuously decreased when clay content was larger than $54 \%$ (Fig. 4c). Notably, the $\mathrm{ES}$ value increased with increasing soil $\mathrm{C} / \mathrm{N}$ ratio (Fig. 4d). The soils under different land uses had similar ES values (Fig. 4e). The ES generally decreased with increasing soil $\mathrm{pH}$ (Fig. 4f). The ES value had a slight decline with silt content (Fig. 4g) and increased faintly with STN content (Fig. 4h).

\section{Discussion}

We identified incubation time as the largest determining factor on biochar-induced $\mathrm{C}$ priming. The positive priming only occurred within the first 775 days of incubation, shifting towards negative priming afterwards (Fig. 2a). It was noted that the number of data points for incubation periods greater than 2 years was smaller than shorter-term incubations. Nevertheless, the trend of negative priming upon ageing in soil is supported by many other studies (Zimmerman et al. 2011; Maestrini et al. 2014a, b; Whitman et al. 2014; Weng et al. 2017). Moreover, a recent meta-analysis showed an average negative priming of $3.8 \%$ on NSOC decomposition (Wang et al. 2015). These results demonstrated that biochar amendment has the potential to increase non-biochar-derived soil C stocks, especially over a longer term. The possible mechanism for positive priming during early incubation is that labile $\mathrm{C}$ within biochar can serve as an energy source for soil microorganisms and stimulate microbial activity shortly after 
Fig. 4 Partial dependence plots showing the variation in biochar priming effect by soil properties used in the BRT model. a Soil organic carbon (SOC) content. b Sand content. c Clay content. d Soil C/N ratio. e Land uses. f Soil pH. g Silt content. h Soil total nitrogen (STN) content. The fitted function shows the relationship between ES and an explanatory variable while all other explanatory variables are kept constant at their mean level. The shading shows the $95 \%$ confidence intervals estimated, and the vertical bars show the standard deviations, from 500 bootstrap samples of the data set. The horizontal dashed line represented a predicted ES value equal to 0
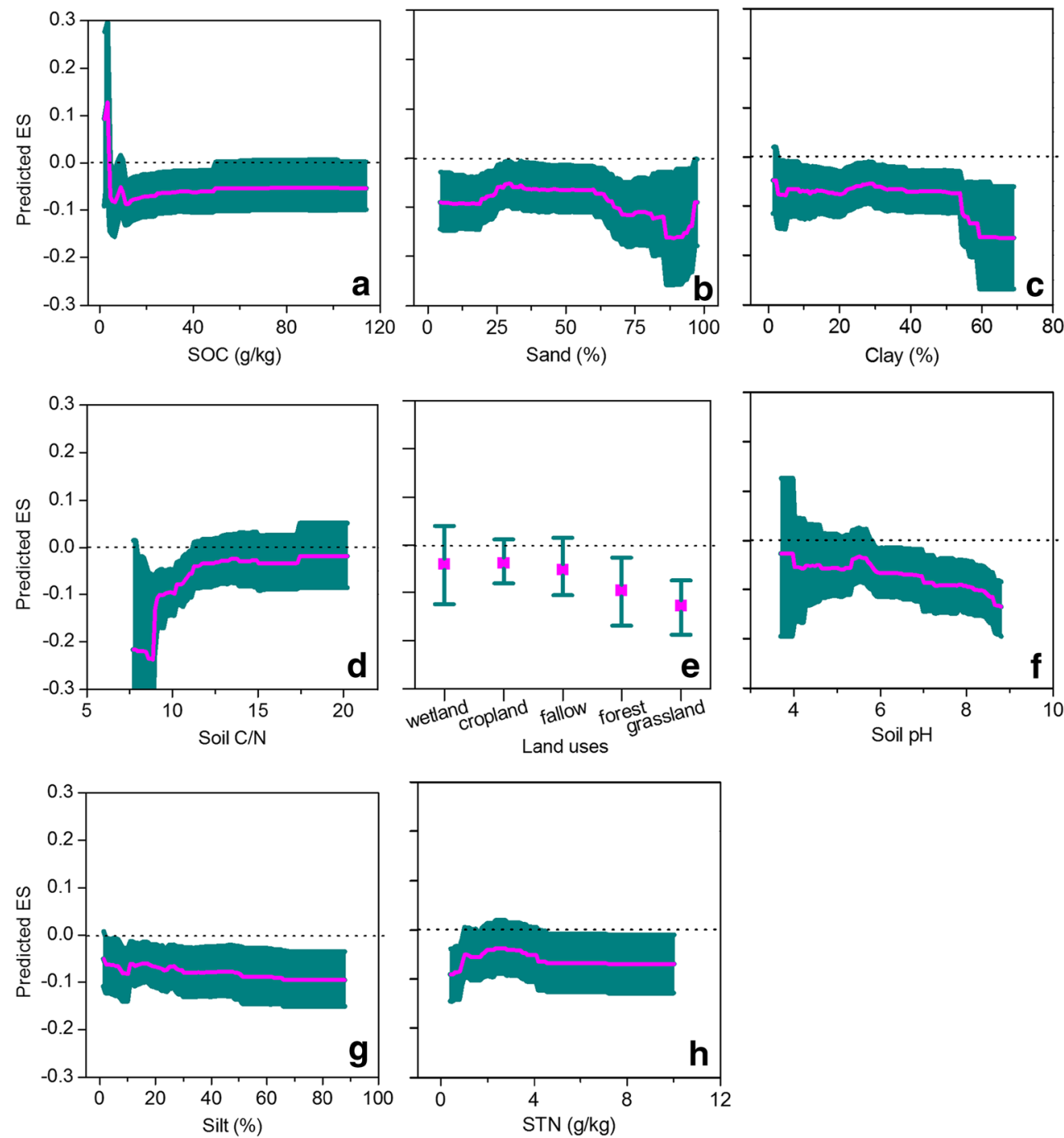

to $50{ }^{\circ} \mathrm{C}$ (Fig. 2c). This was supported by the results of Fang et al. (2015) who observed increasing biochar-induced negative priming from $20^{\circ} \mathrm{C}$ incubation to $40^{\circ} \mathrm{C}$ incubation in four contrasting soils. Fang et al. (2014) suggested that NSOC molecules in soil water may become more flexible and slowly access interior pores of biochar at higher incubation temperature and thus limit accessibility to soil microorganisms. Only a single study examined incubation temperatures above $50{ }^{\circ} \mathrm{C}$ (Fang et al. 2014) thus limiting the information available for the meta-analysis.

Among the biochar properties, biochar $\mathrm{C} / \mathrm{N}$ ratio was the largest determining factor for the $\mathrm{C}$ priming (Fig. 1). The decline of $\mathrm{ES}$ with increasing biochar $\mathrm{C} / \mathrm{N}$ ratio (Fig. 3a) was possibly related to the influence of biochar $\mathrm{N}$ and $\mathrm{C}$ contents on ES. The priming being negative for low $\mathrm{N}$ biochar but positive for high $\mathrm{N}$ biochar was probably because high $\mathrm{N}$ biochar may supply available $\mathrm{N}$ to soil microorganisms in the short term and stimulate microbial activity (Table 1). It was previously assumed that biochar $\mathrm{N}$ had low availability due to it being in heterocyclic structures (Knicker and priming was shown at higher soil incubation temperatures up 
Table 1 The occurring conditions and possible mechanisms for positive and negative priming on native soil organic carbon decomposition following biochar amendment

\begin{tabular}{|c|c|c|}
\hline Biochar & Occurring conditions & Possible mechanisms \\
\hline \multirow[t]{4}{*}{$\begin{array}{l}\text { Positive } \\
\text { priming }\end{array}$} & $\begin{array}{l}\text { Early incubation, low } \mathrm{C} \\
\text { biochar, sludge-derived } \\
\text { biochar }\end{array}$ & $\begin{array}{l}\text { A large amount of labile } \\
\mathrm{C} \text { that stimulates } \\
\text { microbial activities }\end{array}$ \\
\hline & High $\mathrm{N}$ biochar & $\begin{array}{l}\text { Available N supply } \\
\text { stimulates microbial } \\
\text { activities }\end{array}$ \\
\hline & Low soil moisture & $\begin{array}{c}\text { Low mobility of NSOC } \\
\text { molecules to be hardly } \\
\text { adsorbed by biochar }\end{array}$ \\
\hline & Low-C soil & $\begin{array}{l}\text { Small amount of } \\
\text { dissolved NSOC } \\
\text { molecules to be hardly } \\
\text { adsorbed by biochar }\end{array}$ \\
\hline \multirow{6}{*}{$\begin{array}{l}\text { Negative } \\
\text { priming/- } \\
\text { large } \\
\text { negative } \\
\text { priming }\end{array}$} & Late incubation & $\begin{array}{l}\text { Kinetically limited } \\
\text { adsorption and labile } \\
\text { carbon depletion in } \\
\text { biochar }\end{array}$ \\
\hline & Large biochar dose & $\begin{array}{l}\text { Many sorption sites in } \\
\text { biochar that can absorb } \\
\text { a large amount of } \\
\text { NSOC molecules }\end{array}$ \\
\hline & $\begin{array}{l}\text { Long pyrolysis time, high } \\
\text { pyrolysis temperature, } \\
\text { wood-derived biochar }\end{array}$ & $\begin{array}{l}\text { Large biochar surface } \\
\text { area and porosity that } \\
\text { can absorb a large } \\
\text { amount of NSOC } \\
\text { molecules }\end{array}$ \\
\hline & High-pH soil & $\begin{array}{l}\text { Deteriorated soil } \\
\text { environment that } \\
\text { inhibits microbial and } \\
\text { enzyme activities }\end{array}$ \\
\hline & High-clay soil & $\begin{array}{l}\text { Conducive to formation } \\
\text { of soil aggregates } \\
\text { which protect NSOC } \\
\text { molecules }\end{array}$ \\
\hline & Low-C/N soil & $\begin{array}{l}\text { Microbes with no lack of } \\
\mathrm{N} \text { nutrient do not need } \\
\text { to decompose NSOC } \\
\text { to obtain N }\end{array}$ \\
\hline
\end{tabular}

Skjemstad 2000). However, a study using ${ }^{15} \mathrm{~N}$ labelling showed that a portion of the $\mathrm{N}$ within $\mathrm{N}$-rich biochar is available and easily incorporated by soil microbes and plant biomass (Rosa and Knicker 2011). Even if $\mathrm{N}$ in biochar is occluded in aromatic structures, a small amount of $\mathrm{N}$ was found to be mineralized (Schouten et al. 2012). Contrastingly, the priming was positive for low $\mathrm{C}$ biochar but negative for high $\mathrm{C}$ biochar. This can be explained that low $\mathrm{C}$ biochar usually contains a larger labile C fraction (Singh et al. 2012), which can simulate microbial activity (Luo et al. 2013).

Other biochar properties also influenced the $\mathrm{C}$ priming. Pyrolysis time for biochar production was an important factor for the $\mathrm{C}$ priming (Fig. 1). Biochar derived after longer pyrolysis time showed a larger negative priming (Fig. 3c). This could be explained by the fact that surface area and porosity of biochar increase with pyrolysis time (Chen et al. 2008; Yuan et al. 2014; Zhang et al. 2015), thereby facilitating the greater adsorption of NSOC. This explanation for the results of high larger negative priming for biochar derived from higher pyrolysis temperature (Fig. 3g) was similar, as the sorptive capacity of biochar also increases with pyrolysis temperature (Kasozi et al. 2010). Moreover, biochar pH was an influencing factor for $\mathrm{C}$ priming (4.5\% contribution, Fig. 1). There was a trend towards weaker negative priming when $\mathrm{pH}$ was larger than 10.7 (Fig. 3d). However, the data points within this range were extracted from only two studies, thus limiting the information available for the meta-analysis. In addition, biochar-derived $\mathrm{C}$ priming varied with the type of feedstock. Tree- and crop residue-derived biochar had a greater negative priming effect than biochars derived from other feedstock (Fig. 3h). Zimmerman et al. (2011) also observed that tree wood biochar gave greater negative priming than grass biochar. The possible mechanism is that woody biochar generally has a higher surface area and porosity (Hilscher et al. 2009; Lehmann and Joseph 2009; Zimmerman 2010). Contrastingly, sludge-derived biochar showed positive C priming (Fig. 3h). This was likely due to its greater labile $\mathrm{C}$ content than other feedstock (Singh et al. 2012). This was partly supported by McBeath and Smernik (2009) who reported that the biochar derived from paper mill sludge had smaller proportion of aromatic (stable) $\mathrm{C}$ than the biochars derived from other feedstock, e.g. wood, straw or manure.

Soil properties can also influence biochar-derived $\mathrm{C}$ priming. First, SOC content was an important factor for $\mathrm{C}$ priming (Fig. 1). The biochar-derived priming was positive in the low$\mathrm{C}$ soils but negative in the high-C soils, which was similar with Maestrini et al. (2014a) who found that the size of the negative PE was higher when the soil had a higher content in C. The possible reason was that low-C soils usually have a small amount of dissolved NSOC molecules that were hardly adsorbed by biochar, thereby impossibly resulting in negative priming and vice versa. Furthermore, soil texture was an influencing factor on biochar effect on NSOC decomposition (sand and clay giving 4.7 and $4.1 \%$ contributions, respectively, Fig. 1). Soils with higher clay content had larger negative priming (Fig. 4c). Similarly, Wang et al. (2015) observed a trend of positive priming in soils with a clay content $<10 \%$ while negative priming was observed when clay content was $>10 \%$. The possible mechanism was that large amount of clay can encourage the formation of stable soil aggregates $(<$ $250 \mu \mathrm{m}$ ) via organo-mineral interactions between native and/or added organic matter and soil minerals (Golchin et al. 1994; Wagner et al. 2007), thereby protecting NSOC from decomposition (Brodowski et al. 2006; Joseph et al. 2010; Zimmerman et al. 2011).

Biochar-derived $\mathrm{C}$ priming also varied with other soil properties, although they contributed little to the explanation for 
ES. For example, the size of negative priming decreased with soil C/N ratio (Fig. 4e). The reason could be that microorganisms in soils with high $\mathrm{C} / \mathrm{N}$ ratio was lacking $\mathrm{N}$ nutrient, so they could need to decompose the native SOM more intensely to obtain available $\mathrm{N}$ for growth (Zhang et al. 2013), thereby resulting in low net negative priming. Another factor was soil $\mathrm{pH}$. Larger negative priming in alkaline soil was observed than in acidic soil (Fig. 4h). Acidic soils may have less $\mathrm{pH}-$ related constraints to microbial activity after biochar amendment (Van Zwieten et al. 2010), but alkaline soil may become more alkaline and suppress soil microbial activity, thereby triggering larger negative priming.

Our results showed that incubation conditions and biochar properties played more important roles in driving biocharinduced soil $\mathrm{C}$ priming than soil properties (Fig. 1). This seemed to be different from the drivers for the soil $\mathrm{C}$ priming induced by fresh organic materials (no charred). Previous meta-analyses have shown that the priming of NSOC decomposition by fresh organic material was closely related to soil parameters (e.g. SOC, STN, soil C/N ratio or soil clay content and land use type) rather than the properties of the added materials (Zhang et al. 2013; Luo et al. 2016). This difference in drivers could be due to the sorption of NSOC by biochar, as a main mechanism for the negative $\mathrm{C}$ priming as discussed in Maestrini et al. (2014a), which is yet unlikely to occur after fresh organic matter addition.

Although our analysis provides new insights into the response of NSOC decomposition to biochar amendment, several knowledge gaps are still apparent. Firstly, the duration of biochar-induced negative priming was evident for 7 years in our meta-analysis. Further, negative priming has been detected a decade after biochar was applied to a ferrosol under subtropical pasture (Weng et al. 2017), indicating the potential for biochar amendment to support soil $\mathrm{C}$ sequestration beyond the stable $\mathrm{C}$ content of biochar alone. However, a paucity of longer-term studies (lasting for decades) using $\mathrm{C}$ isotope differentiation between biochar C and NSOC remains, especially under varying soil types and climatic conditions. Considering biochar would persist in soils on a centennial scale (Wang et al. 2015), future studies need to test whether the negative priming of biochar can last for so long.

\section{Conclusions}

Our synthesis critically evaluated the influencing factors on the biochar-induced soil $\mathrm{C}$ priming in laboratory settings. We demonstrated that biochar properties and incubation conditions have larger impacts on the priming than soil properties. We also identified the factors ( $>4 \%$ contribution) driving biochar-induced priming in incubation studies, these being incubation time and soil moisture, biochar $\mathrm{C} / \mathrm{N}$ ratio and $\mathrm{N}$ content and $\mathrm{pH}$, pyrolysis time during biochar production and
SOC content and soil texture. We revealed that biochar amendment showed positive priming during early incubation, for the biochars with low $\mathrm{C}$ content or high $\mathrm{N}$ content or derived from sludge and in the soils with low $\mathrm{C}$ content or with low moisture. In the other circumstances, it would show negative priming. These insights can help us to better predict the effect of biochar amendment on soil $\mathrm{C}$ cycling.

Acknowledgements We are grateful to two anonymous reviewers for their insightful advice on an earlier version of this manuscript. We thank all the researchers whose data were included in this meta-analysis. This work was supported by the National Science Foundation of China (grant numbers 41601307, 31330011, 41630755), State Key Laboratory of Forest and Soil Ecology (grant number LFSE2015-06) and the National Key Research and Development Program of China (grant number 2016YFD0200304).

\section{References}

Brodowski S, John B, Flessa H, Amelung W (2006) Aggregate-occluded black carbon in soil. Eur J Soil Sci 57(4):539-546. https://doi.org/ 10.1111/j.1365-2389.2006.00807.x

Bruun S, El-Zehery T (2012) Biochar effect on the mineralization of soil organic matter. Pesq Agrop Brasileira 47(5):665-671. https://doi. org/10.1590/S0100-204X2012000500005

Carslaw DC, Taylor PJ (2009) Analysis of air pollution data at a mixed source location using boosted regression trees. Atmos Environ 43(22-23):3563-3570. https://doi.org/10.1016/j.atmosenv.2009.04. 001

Chen B, Zhou D, Zhu L (2008) Transitional adsorption and partition of nonpolar and polar aromatic contaminants by biochars of pine needles with different pyrolytic temperatures. Environ Sci Technol 42(14):5137-5143. https://doi.org/10.1021/es8002684

Ciais P, Sabine C, Bala G, Bopp L, Brovkin V, Canadell J, Chhabra A, DeFries R, Galloway J, Heimann M, Jones C, Quéré CL, Myneni RB, Piao S, Thornton P (2013) Carbon and other biogeochemical cycles. In: Stocker TF et al (eds) The physical science basis. Contribution of Working Group I to the Fifth Assessment Report of the Intergovernmental Panel on Climate Change. Cambridge University Press, Cambridge, pp 465-570

Cross A, Sohi SP (2011) The priming potential of biochar products in relation to labile carbon contents and soil organic matter status. Soil Biol Biochem 43(10):2127-2134. https://doi.org/10.1016/j.soilbio. 2011.06.016

Cui J, Ge TD, Kuzyakov Y, Nie M, Fang CM, Tang BP, Zhou CL (2017) Interactions between biochar and litter priming: a three-source C-14 and delta C-13 partitioning study. Soil Biol Biochem 104:49-58. https://doi.org/10.1016/j.soilbio.2016.10.014

De'Ath G (2007) Boosted trees for ecological modeling and prediction. Ecology 88(1):243-251. https://doi.org/10.1890/0012-9658(2007) 88[243:BTFEMA]2.0.CO;2

Dharmakeerthi RS, Hanley K, Whitman T, Woolf D, Lehmann J (2015) Organic carbon dynamics in soils with pyrogenic organic matter that received plant residue additions over seven years. Soil Biol Biochem 88:268-274. https://doi.org/10.1016/j.soilbio.2015.06.003

Elith J, Leathwick JR, Hastie T (2008) A working guide to boosted regression trees. J Anim Ecol 77(4):802-813. https://doi.org/10.1111/ j.1365-2656.2008.01390.x

Fang Y, Singh BP, Singh B (2014) Temperature sensitivity of biochar and native carbon mineralisation in biochar-amended soils. Agric 
Ecosyst Environ 191:158-167. https://doi.org/10.1016/j.agee.2014. 02.018

Fang Y, Singh B, Singh BP (2015) Effect of temperature on biochar priming effects and its stability in soils. Soil Biol Biochem 80: 136-145. https://doi.org/10.1016/j.soilbio.2014.10.006

Farrell M, Kuhn TK, Macdonald LM, Maddern TM, Murphy DV, Hall PA, Singh BP, Baumann K, Krull ES, Baldock JA (2013) Microbial utilisation of biochar-derived carbon. Sci Total Environ 465:288297. https://doi.org/10.1016/j.scitotenv.2013.03.090

Golchin A, Oades J, Skjemstad J, Clarke P (1994) Study of free and occluded particulate organic matter in soils by solid state ${ }^{13} \mathrm{C} \mathrm{CP} /$ MAS NMR spectroscopy and scanning electron microscopy. Soil Res 32(2):285-309. https://doi.org/10.1071/SR9940285

Herath H, Camps-Arbestain M, Hedley MJ, Kirschbaum MUF, Wang T, van Hale R (2015) Experimental evidence for sequestering $\mathrm{C}$ with biochar by avoidance of $\mathrm{CO}_{2}$ emissions from original feedstock and protection of native soil organic matter. GCB Bioenergy 7(3):512526. https://doi.org/10.1111/gcbb.12183

Hilscher A, Heister K, Siewert C, Knicker H (2009) Mineralisation and structural changes during the initial phase of microbial degradation of pyrogenic plant residues in soil. Org Geochem 40(3):332-342. https://doi.org/10.1016/j.orggeochem.2008.12.004

Jones D, Murphy D, Khalid M, Ahmad W, Edwards-Jones G, DeLuca T (2011) Short-term biochar-induced increase in soil $\mathrm{CO}_{2}$ release is both biotically and abiotically mediated. Soil Biol Biochem 43(8): 1723-1731. https://doi.org/10.1016/j.soilbio.2011.04.018

Joseph S, Camps-Arbestain M, Lin Y, Munroe P, Chia C, Hook J, Van Zwieten L, Kimber S, Cowie A, Singh B (2010) An investigation into the reactions of biochar in soil. Aust J Soil Res 48(7):501-515. https://doi.org/10.1071/SR10009

Kasozi GN, Zimmerman AR, Nkedi-Kizza P, Gao B (2010) Catechol and humic acid sorption onto a range of laboratory-produced black carbons (biochars). Environ Sci Technol 44(16):6189-6195. https:// doi.org/10.1021/es1014423

Keith A, Singh B, Singh BP (2011) Interactive priming of biochar and labile organic matter mineralization in a smectite-rich soil. Environ Sci Technol 45(22):9611-9618. https://doi.org/10.1021/es202186j

Kerré B, Hernandez-Soriano MC, Smolders E (2016) Partitioning of carbon sources among functional pools to investigate short-term priming effects of biochar in soil: a C-13 study. Sci Total Environ 547: 30-38. https://doi.org/10.1016/j.scitotenv.2015.12.107

Knicker H, Skjemstad JO (2000) Nature of organic carbon and nitrogen in physically protected organic matter of some Australian soils as revealed by solid-state ${ }^{13} \mathrm{C}$ and ${ }^{15} \mathrm{~N}$ NMR spectroscopy. Soil Res 38(1):113-128. https://doi.org/10.1071/SR99024

Kuzyakov Y, Subbotina I, Chen H, Bogomolova I, Xu X (2009) Black carbon decomposition and incorporation into soil microbial biomass estimated by ${ }^{14} \mathrm{C}$ labeling. Soil Biol Biochem 41(2):210-219. https://doi.org/10.1016/j.soilbio.2008.10.016

Lehmann J (2007) A handful of carbon. Nature 447(7141):143-144. https://doi.org/10.1038/447143a

Lehmann J, Joseph S (2009) Biochar for environmental management: science and technology. Earthscan, London

Lehmann J, Gaunt J, Rondon M (2006) Bio-char sequestration in terrestrial ecosystems - a review. Mitig Adapt Strateg Glob 11:395-419

Lehmann J, Rillig MC, Thies J, Masiello CA, Hockaday WC, Crowley D (2011) Biochar effects on soil biota - a review. Soil Biol Biochem 43(9):1812-1836. https://doi.org/10.1016/j.soilbio.2011.04.022

Lu N, Liu X-R, Du Z-L, Wang Y-D, Zhang Q-Z (2014a) Effect of biochar on soil respiration in the maize growing season after 5 years of consecutive application. Soil Res 52(5):505-512. https://doi.org/ 10.1071/SR13239

Lu WW, Ding WX, Zhang JH, Li Y, Luo JF, Bolan N, Xie ZB (2014b) Biochar suppressed the decomposition of organic carbon in a cultivated sandy loam soil: a negative priming effect. Soil Biol Biochem $76: 12-21$
Luo Y, Durenkamp M, De Nobili M, Lin Q, Brookes PC (2011) Short term soil priming effects and the mineralisation of biochar following its incorporation to soils of different $\mathrm{pH}$. Soil Biol Biochem 43(11): 2304-2314. https://doi.org/10.1016/j.soilbio.2011.07.020

Luo Y, Durenkamp M, De Nobili M, Lin Q, Devonshire BJ, Brookes PC (2013) Microbial biomass growth, following incorporation of biochars produced at $350^{\circ} \mathrm{C}$ or $700^{\circ} \mathrm{C}$, in a silty-clay loam soil of high and low pH. Soil Biol Biochem 57:513-523. https://doi.org/10. 1016/j.soilbio.2012.10.033

Luo Z, Wang E, Sun OJ (2016) A meta-analysis of the temporal dynamics of priming soil carbon decomposition by fresh carbon inputs across ecosystems. Soil Biol Biochem 101:96-103. https://doi.org/10. 1016/j.soilbio.2016.07.011

Luo Y, Lin Q, Durenkamp M, Kuzyakov Y (2017) Does repeated biochar incorporation induce further soil priming effect? J Soils Sediments. https://doi.org/10.1007/s11368-017-1705-5

Maestrini B, Nannipieri P, Abiven S (2014a) A meta-analysis on pyrogenic organic matter induced priming effect. GCB Bioenergy 7: $577-590$

Maestrini B, Herrmann AM, Nannipieri P, Schmidt MWI, Abiven S (2014b) Ryegrass-derived pyrogenic organic matter changes organic carbon and nitrogen mineralization in a temperate forest soil. Soil Biol Biochem 69:291-301. https://doi.org/10.1016/j.soilbio.2013. 11.013

Malghani S, Juschke E, Baumert J, Thuille A, Antonietti M, Trumbore S, Gleixner G (2015) Carbon sequestration potential of hydrothermal carbonization char (hydrochar) in two contrasting soils; results of a 1-year field study. Biol Fertil Soils 51(1):123-134. https://doi.org/ 10.1007/s00374-014-0980-1

McBeath AV, Smernik RJ (2009) Variation in the degree of aromatic condensation of chars. Org Geochem 40(12):1161-1168. https:// doi.org/10.1016/j.orggeochem.2009.09.006

Murray J, Keith A, Singh B (2015) The stability of low- and high-ash biochars in acidic soils of contrasting mineralogy. Soil Biol Biochem 89:217-225. https://doi.org/10.1016/j.soilbio.2015.07.014

Naisse C, Girardin C, Davasse B, Chabbi A, Rumpel C (2015a) Effect of biochar addition on $\mathrm{C}$ mineralisation and soil organic matter priming in two subsoil horizons. J Soils Sediments 15(4):825-832. https:// doi.org/10.1007/s11368-014-1002-5

Naisse C, Girardin C, Lefevre R, Pozzi A, Maas R, Stark A, Rumpel C (2015b) Effect of physical weathering on the carbon sequestration potential of biochars and hydrochars in soil. GCB Bioenergy 7(3): 488-496. https://doi.org/10.1111/gcbb. 12158

Nguyen BT, Koide RT, Dell C, Drohan P, Skinner H, Adler PR, Nord A (2014) Turnover of soil carbon following addition of switchgrassderived biochar to four soils. Soil Sci Soc Am J 78(2):531-537. https://doi.org/10.2136/sssaj2013.07.0258

Nguyen DB, Rose MT, Rose TJ, Morris SG, Van Zwieten L (2016) Impact of glyphosate on soil microbial biomass and respiration: a meta-analysis. Soil Biol Biochem 92:50-57. https://doi.org/10. 1016/j.soilbio.2015.09.014

R Development Core Team (2012) R: A language and environment for statistical computing. R Foundation for Statistical Computing, Vienna. http://www.R-project.org

Rittl T, Novotny E, Balieiro F, Hoffland E, Alves B, Kuyper T (2015) Negative priming of native soil organic carbon mineralization by oilseed biochars of contrasting quality. Eur J Soil Sci 66(4):714 721. https://doi.org/10.1111/ejss. 12257

Robinson JW (2008) Regression tree boosting to adjust health care cost predictions for diagnostic mix. Health Serv Res 43(2):755-772. https://doi.org/10.1111/j.1475-6773.2007.00761.x

Rosa J, Knicker H (2011) Bioavailability of N released from Nrich pyrogenic organic matter: an incubation study. Soil Biol Biochem 43(12):2368-2373. https://doi.org/10.1016/j.soilbio. 2011.08.008 
Sagrilo E, Jeffery S, Hoffland E, Kuyper TW (2014) Emission of $\mathrm{CO}_{2}$ from biochar-amended soils and implications for soil organic carbon. GCB Bioenergy 7:1294-1304

Santos F, Torn MS, Bird JA (2012) Biological degradation of pyrogenic organic matter in temperate forest soils. Soil Biol Biochem 51:115 124. https://doi.org/10.1016/j.soilbio.2012.04.005

Schmidt MWI, Skjemstad JO, Jäger C (2002) Carbon isotope geochemistry and nanomorphology of soil black carbon: black chernozemic soils in central Europe originate from ancient biomass burning. Glob Biogeochem Cycles 16:1123

Schouten S, van Groenigen JW, Oenema O, Cayuela ML (2012) Bioenergy from cattle manure? Implications of anaerobic digestion and subsequent pyrolysis for carbon and nitrogen dynamics in soil. GCB Bioenergy 4(6):751-760. https://doi.org/10.1111/j.1757-1707. 2012.01163.X

Sheng Y, Zhan Y, Zhu L (2016) Reduced carbon sequestration potential of biochar in acidic soil. Sci Total Environ 572:129-137. https://doi. org/10.1016/j.scitotenv.2016.07.140

Singh BP, Cowie AL (2014) Long-term influence of biochar on native organic carbon mineralisation in a low-carbon clayey soil. Sci Rep 4:3687

Singh BP, Cowie AL, Smernik RJ (2012) Biochar carbon stability in a clayey soil as a function of feedstock and pyrolysis temperature. Environ Sci Technol 46(21):11770-11778. https://doi.org/10.1021/ es302545b

Stewart CE, Zheng JY, Botte J, Cotrufo MF (2013) Co-generated fast pyrolysis biochar mitigates green-house gas emissions and increases carbon sequestration in temperate soils. GCB Bioenergy 5(2):153164. https://doi.org/10.1111/gcbb.12001

Van Zwieten L, Kimber S, Morris S, Chan K, Downie A, Rust J, Joseph S, Cowie A (2010) Effects of biochar from slow pyrolysis of papermill waste on agronomic performance and soil fertility. Plant Soil 327(1-2):235-246. https://doi.org/10.1007/s11104-009-0050-x

Ventura M, Alberti G, Viger M, Jenkins JR, Girardin C, Baronti S, Zaldei A, Taylor G, Rumpel C, Miglietta F (2015) Biochar mineralization and priming effect on SOM decomposition in two European short rotation coppices. GCB Bioenergy 7(5):1150-1160. https://doi.org/ 10.1111/gcbb. 12219

Wagner S, Cattle SR, Scholten T (2007) Soil-aggregate formation as influenced by clay content and organic-matter amendment. J Plant Nutr Soil Sci 170(1):173-180. https://doi.org/10.1002/jpln. 200521732

Wang J, Xiong Z, Kuzyakov Y (2015) Biochar stability in soil: metaanalysis of decomposition and priming effects. GCB Bioenergy 8: 512-523

Wardle DA, Nilsson M-C, Zackrisson O (2008) Fire-derived charcoal causes loss of forest humus. Science 320(5876):629-629. https:// doi.org/10.1126/science.1154960

Weng ZH, Van Zwieten L, Singh B, Kimber S, Morris S, Cowie A, Macdonald LM (2015) Plant-biochar interactions drive the negative priming of soil organic carbon in an annual ryegrass field system. Soil Biol Biochem 90:111-121. https://doi.org/10.1016/j.soilbio. 2015.08.005
Weng ZH, Van Zwieten L, Singh BP, Tavakkoli E, Joseph S, Macdonald LM, Rose TJ, Rose MT, Kimber SW, Morris S (2017) Biochar built soil carbon over a decade by stabilizing rhizodeposits. Nat Clim Chang 7(5):371-376. https://doi.org/10.1038/nclimate3276

Whitman T, Enders A, Lehmann J (2014) Pyrogenic carbon additions to soil counteract positive priming of soil carbon mineralization by plants. Soil Biol Biochem 73:33-41. https://doi.org/10.1016/j. soilbio.2014.02.009

Woolf D, Lehmann J (2012) Modelling the long-term response to positive and negative priming of soil organic carbon by black carbon. Biogeochemistry 111(1-3):83-95. https://doi.org/10.1007/s10533012-9764-6

Woolf D, Amonette JE, Street-Perrott FA, Lehmann J, Joseph S (2010) Sustainable biochar to mitigate global climate change. Nat Commun $1: 56$

Yousaf B, Liu G, Wang R, Abbas Q, Imtiaz M, Liu R (2017) Investigating the biochar effects on $\mathrm{C}$-mineralization and sequestration of carbon in soil compared with conventional amendments using the stable isotope ( $813 \mathrm{C}$ ) approach. GCB Bioenergy 9(6):1085-1099. https:// doi.org/10.1111/gcbb.12401

Yu L, Tang J, Zhang R, Wu Q, Gong M (2013) Effects of biochar application on soil methane emission at different soil moisture levels. Biol Fertil Soils 49(2):119-128. https://doi.org/10.1007/s00374012-0703-4

Yuan H, Lu T, Wang Y, Huang H, Chen Y (2014) Influence of pyrolysis temperature and holding time on properties of biochar derived from medicinal herb (radix isatidis) residue and its effect on soil $\mathrm{CO}_{2}$ emission. J Anal Appl Pyrol 110:277-284. https://doi.org/10.1016/ j.jaap.2014.09.016

Zhang Y, Chen HY, Reich PB (2012) Forest productivity increases with evenness, species richness and trait variation: a global meta-analysis. J Ecol 100(3):742-749. https://doi.org/10.1111/j.1365-2745.2011. 01944.x

Zhang W, Wang X, Wang S (2013) Addition of external organic carbon and native soil organic carbon decomposition: a meta-analysis. PLoS One 8(2):e54779. https://doi.org/10.1371/journal.pone. 0054779

Zhang J, Liu J, Rongle L (2015) Effects of pyrolysis temperature and heating time on biochar obtained from the pyrolysis of straw and lignosulfonate. Bioresour Technol 176:288-291. https://doi.org/10. 1016/j.biortech.2014.11.011

Zhang W, Yuan S, Hu N, Lou Y, Wang S (2015) Predicting soil fauna effect on plant litter decomposition by using boosted regression trees. Soil Biol Biochem 82:81-86. https://doi.org/10.1016/j. soilbio.2014.12.016

Zimmerman AR (2010) Abiotic and microbial oxidation of laboratoryproduced black carbon (biochar). Environ Sci Technol 44(4):12951301. https://doi.org/10.1021/es903140c

Zimmerman AR, Gao B, Ahn MY (2011) Positive and negative carbon mineralization priming effects among a variety of biochar-amended soils. Soil Biol Biochem 43(6):1169-1179. https://doi.org/10.1016/ j.soilbio.2011.02.005 